\title{
A Non-Enzymatic Sensor Based on Fc-CHIT/CNT@Cu Nanohybrids for Electrochemical Detection of Glucose
}

\author{
Fang Wang ${ }^{1,2, *}$, Sheng $\mathrm{Hu}^{1}{ }^{1}$, Fengna Shi ${ }^{1}$, Kexin Huang ${ }^{1}$ and Jiarui $\mathrm{Li}^{1}$ \\ 1 Nanjing Forestry Univ, Coll Chem Engn, Nanjing 210037, Jiangsu, China; drwatson1995@163.com (S.H.); \\ shi1355128616@163.com (F.S.); kexin0722@163.com (K.H.); lijiarui11251004@163.com (J.L.) \\ 2 Nanjing Forestry Univ, Coinnovat Ctr Efficient Proc \& Utilizat Forest Re, Nanjing 210037, Jiangsu, China \\ * Correspondence: wangfang@njfu.edu.cn
}

Received: 6 September 2020; Accepted: 14 October 2020; Published: 20 October 2020

\begin{abstract}
Herein, a composite structure, consisting of $\mathrm{Cu}$ nanoparticles (NPs) deposited onto carbon nanotubes and modified with ferrocene-branched chitosan, was prepared in order to develop a nonenzymatic electrochemical glucose biosensor ferrocene-chitosan/carbon nanotube@ $\mathrm{Cu}$ (Fc-CHIT/CNT@Cu). The elemental composition of the carbon nanohybrids, morphology and structure were characterized by various techniques. Electrochemical impedance spectroscopy (EIS) was used to study the interfacial properties of the electrodes. Cyclic voltammetry (CV) and chronoamperometry methods in alkaline solution were used to determine glucose biosensing properties. The synergy effect of $\mathrm{Cu}$ NPs and Fc on current responses of the developed electrode resulted in good glucose sensitivity, including broad linear detection between $0.2 \mathrm{mM}$ and $22 \mathrm{mM}$, a low detection limit of $13.52 \mu \mathrm{M}$ and sensitivity of $1.256 \mu \mathrm{AmM}^{-1} \mathrm{~cm}^{-2}$. Moreover, the modified electrode possessed long-term stability and good selectivity in the presence of ascorbic acid, dopamine and uric acid. The results indicated that this inexpensive electrode had potential application for non-enzymatic electrochemical glucose detection.
\end{abstract}

Keywords: carbon nanotube; chitosan; copper nanoparticles; ferrocene; electrochemical sensor; glucose; non-enzymatic

\section{Introduction}

Today, diabetes is a worldwide health problem. The literature states that there were 451 million (18-99 years) people around the world suffering from diabetes in 2017, and this number is estimated to be 693 million by 2045. Additionally, according to the estimation, almost half of diabetic patients $(49.7 \%)$ do not get diagnosed [1]. Diabetes is a chronic disease that can cause some complications in severe cases, such as heart attack, stroke, kidney failure and nerve damage [2-4]. It is important to measure blood glucose levels during treatment of diabetes, especially in the early stages. In this case, new, more rapid, sensitive and selective glucose concentration detection methods are urgently needed. Using portable electronic devices to directly detect glucose is a convenient diagnostic method in the initial steps. A literature survey found that glucose sensors can be divided into two categories: enzyme-based sensors [5,6] and enzyme-free sensors [7,8]. Enzyme-based electrochemical biosensors are complex, expensive and affected by temperature and $\mathrm{pH}$ due to enzyme activity. Therefore, more concern has been brought to developing non-enzymatic electrochemical methods with high sensitivity, low detection limit, fast response speed, high reliability and good selectivity. In particular, various glucose sensors, based on nanomaterials' electrocatalytic action, have made up for the deficiency of traditional enzyme-based sensors. 
Metal nanoparticles, such as $\mathrm{Au}$ [9], $\mathrm{Ni}$ [10] and Co nanoparticles [11], are often used in construction of nonenzymatic sensors. Copper is an essential micronutrient for all living organisms, in addition to its good biocompatibility, low cost and environmentally friendly properties, which make copper nanoparticles attractive catalysts [12]. Carbon nanotubes are often used for metal nanoparticle support due to their relatively high chemical stability, large surface area, strong adsorption capacity and excellent electrical conductivity $[13,14]$. Work has been done using carbon nanotubes as a template to support metal nanoparticle catalysts [15]. In principle, metal nanoparticles are formed on the surface of carbon nanotubes, rather than on sidewall defect sites [16]. Therefore, the surface of carbon nanotubes needs to be functionalized to obtain uniformly distributed nanoparticles by covalent or noncovalent interactions $[17,18]$.

Carrier-catalyst composites affect sensor performance in their manufacturing [19-21]. The performance of the carrier for immobilizing metal nanoparticles is one of the factors affecting the catalyst's performance, because they affect dispersibility, conductivity and stability. These are the prerequisites for stable and effective sensor operation [19]. Natural polysaccharide chitosan (CHIT) is derived from deacetylation of chitin, and it has good film-forming ability, adhesion, excellent biocompatibility and high hydroxyl and amino content $[22,23]$. However, CHIT application in electrochemical sensors is limited due to its non-conductive properties. To improve its conductance, attempts to introduce metal elements were made. Ferrocene $(\mathrm{Fc})$ and ferrocene-based derivatives have suitable electrochemical properties, such as stable redox state, reversibility and regeneration at low potential. Therefore, they are often used as good electronic conductors [24,25]. The purpose of adding Fc to the prepared composite material was to increase the electron transfer rate, thereby improving the electrochemical performance of the glucose sensor.

Herein, copper nanoparticles were decorated on acidified multiwalled carbon nanotubes (CNT@Cu) using a chemical reduction method. In pursuit of constructing a highly sensitive and wide linear range amperometric biosensor for glucose detection, a novel, enzyme-free glucose sensor was prepared using a glassy carbon electrode covered with ferrocene-branched chitosan/CNT@Cu nanohybrids. Because the materials had these advantages, the composite electrodes were fabricated to make use of their synergistic electrochemical effects.

\section{Materials and Methods}

\subsection{Materials}

Chitosan was purchased from Beijing Solaribio Science \& Technology Co. Ltd. (Beijing, China), with a degree of deacetylation $>90.0 \%$. D-(+)-glucose anhydrous $(\geq 98.0 \%)$, ferrocene formaldehyde, dopamine $(\geq 98.0 \%)$, uric acid $(\geq 98.0 \%)$ and ascorbic acid $(\geq 98.0 \%)$ were purchased from Aladdin Chemical Reagent Inc. (Shanghai, China). MWCNTs (Multiwall carbon nanotubes) (OD $<8 \mathrm{~nm}$, purity $>95 \%$, ash $<1.5 \%$ ) with a length of 10-30 $\mu \mathrm{m}$ were obtained from Xianfeng Nano Material Technology Co., Ltd. (Nanjing, China). Carboxylated MWCNTs were formed using an $\mathrm{HNO}_{3}$ solution. All other used chemicals were of analytical grade.

\subsection{Apparatus}

FT-IR spectra of all the samples were obtained and analyzed using a Fourier transform infrared instrument (FT-IR360, Nicolet, Wisconsin, WI, USA), using KBr pellets in the wavenumber range of $400-4000 \mathrm{~cm}^{-1}$. The UV spectrum of the samples was obtained by an ultraviolet spectrophotometer (SHIMADZU, Kyoto, Japan). A thermal analyzer (Q5000IR, Delaware, TA, USA) was used in the temperature range of $20-600{ }^{\circ} \mathrm{C}$, heating rate of $10{ }^{\circ} \mathrm{C} / \mathrm{min}$ and nitrogen flow rate of $10 \mathrm{~mL} / \mathrm{min}$ to study thermal properties of pure chitosan, ferrocene and modified chitosan.

The internal feature of modified electrodes was characterized using a JEM-1400 transmission electron microscope (TEM, Tokyo, Japan). Before the test, a drop of diluted modified electrode material suspension was added onto a glassy carbon electrode (GCE), and a thin-film TEM test sample was 
obtained after drying at room temperature. Fc-CHIT/CNT@Cu nanohybrids were prepared for a thin film, and SEM images were obtained using a Hitachi S4800 scanning electron microscope.

Cyclic voltammetry (CV) (potential range was -0.8 to $0.8 \mathrm{~V}$ and scan rate was $10 \mathrm{mV} / \mathrm{s}$ ), electrochemical impedance spectroscopy (EIS) (frequency range was $0.01-100,000 \mathrm{~Hz}$ ), amperometric $\mathrm{i}-\mathrm{t}$ curve (i-t) (potential window was $0.44 \mathrm{~V}$ ) were all performed using a $\mathrm{CHI} 760 \mathrm{E}$ electrochemical workstation (Shanghai, China) with a conventional three-electrode system, which consisted of a glassy carbon electrode (the diameter was $3 \mathrm{~mm}$ ) as the working electrode, a platinum wire as the counter electrode (CE) and a saturated calomel electrode (SCE) as the reference electrode. In this article, we used $\mathrm{CV}$, EIS and i-t to test the electrochemical performance of different electrodes. In the i-t test, the initial electrolyte was a $20 \mathrm{~mL} \mathrm{NaOH}$ solution $(0.1 \mathrm{M})$, and the volume of the glucose solution was $10 \mu \mathrm{L}$ for each addition.

\subsection{Synthesis of Ferrocene-Branched Chitosan}

Chitosan was modified with ferrocene according to the literature [26]. Briefly, $90 \mathrm{mg}$ of CHIT was dissolved in $20 \mathrm{~mL}$ of acetic acid solution (1\%). Fifteen milligrams of $\mathrm{FC}_{\mathrm{C}}$ was dissolved in $15 \mathrm{~mL}$ of methanol and then added into the CHIT solution and stirred for $1 \mathrm{~h}$. After adding $\mathrm{NaCNBH}_{3}$, the reaction mixture was stirred for $24 \mathrm{~h}$, and finally a $5 \% \mathrm{NaOH}$ solution was added to the precipitate. The yellow product was collected and washed alternately with water and methanol. The solid product was freeze-dried to obtain Fc-CHIT.

\subsection{Decoration of $\mathrm{Cu}$ NPs onto Carbon Nanotubes (CNT@Cu)}

CNT@Cu nanocomposites were prepared using a chemical reduction method with a $\mathrm{Cu}$ salt and acidified multiwalled carbon nanotubes [27]. Firstly, $20 \mathrm{~mL}$ of CNT suspension $(12.5 \mathrm{mg} / \mathrm{mL})$ was added into a $20 \mathrm{~mL} \mathrm{CuSO}$ ( $(10 \mathrm{mmol} / \mathrm{L})$ and $20 \mathrm{~mL}$ sodium citrate $(40 \mathrm{mmol} / \mathrm{L})$ solution, and magnetically stirred for $1 \mathrm{~h}$. Then, a certain amount of $0.1 \mathrm{M} \mathrm{NaBH}_{4}$ solution was slowly added and stirred for another $1 \mathrm{~h}$ under ice-bath conditions. Finally, the obtained solution was washed, filtered and freeze-dried to obtain Cu-decorated CNT (CNT@Cu).

\subsection{Preparation of the Modified Electrodes}

The modified electrode Fc-CHIT/CNT@Cu (Fc-CHIT/CNT, CHIT/CNT@Cu or CHIT/CNT) was prepared using a solution casting method. GCE was polished with $0.3 \mathrm{~mm}$ alumina powder and sonicated in ethanol and distilled water for 3 min each. Typically, 0.4 mg of CNT@Cu (or CNT) was introduced into $1 \mathrm{~mL}$ of Fc-CHIT (or CHIT) solution, and the mixture was sonicated for $1 \mathrm{~h}$. After that, $5 \mu \mathrm{L}$ suspended droplets were added to the surface of GCE, and the electrode was dried at room temperature. Thus, a nonenzymatic electrochemical biosensor, based on CHIT/CNT nanohybrids, was obtained.

\section{Results}

\subsection{Characterization of Composites}

The chitosan modification reaction and resulting product analysis are shown in Figure 1. From the FT-IR spectra in Figure 1a, the chitosan spectrum showed characteristic peaks at $1659 \mathrm{~cm}^{-1}$ and $1596 \mathrm{~cm}^{-1}$, which were related to the amide I and II bands of CHIT. The aldehyde group in Fc-CHO reacted with the amino group in chitosan, and a covalent bond was formed by Schiff-based reaction (i.e., -C-N-) [26]. Therefore, the Fc-CHO characteristic peak at $1684 \mathrm{~cm}^{-1}$ disappeared in the Fc-CHIT spectrum. At the same time, the Fc-CHIT spectrum showed a new absorption band at $481 \mathrm{~cm}^{-1}$ due to the M-ring extension and ring inclination of the ferrocene group. Furthermore, another absorption band at $890 \mathrm{~cm}^{-1}$ also indicated that the ferrocene group was present in Fc-CHIT. The absorption peaks between $2860 \mathrm{~cm}^{-1}$ and $2970 \mathrm{~cm}^{-1}$ in all three samples were due to the existence of $-\mathrm{CH}_{3}$ and $-\mathrm{CH}_{2}$, while the peak around $1070 \mathrm{~cm}^{-1}$ was the $\mathrm{C}-\mathrm{O}$ absorption band. Furthermore, the UV spectra of CHIT, 
Fc and Fc-CHIT also indicated successful synthesis of Fc-CHIT, shown in Figure 1c [28]. From the spectra, CHIT and Fc-CHO had characteristic absorption peaks at 220 and $302 \mathrm{~nm}$ as well as 231 and $342 \mathrm{~nm}$, respectively. However, Fc-CHIT showed absorption bands at $226 \mathrm{~nm}$ and $322 \mathrm{~nm}$, which was caused by an Fc group grafted to chitosan.

(a)

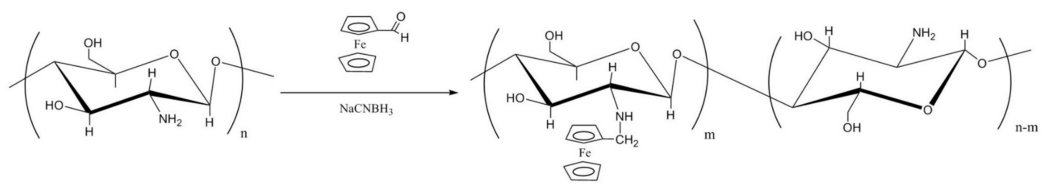

(b)

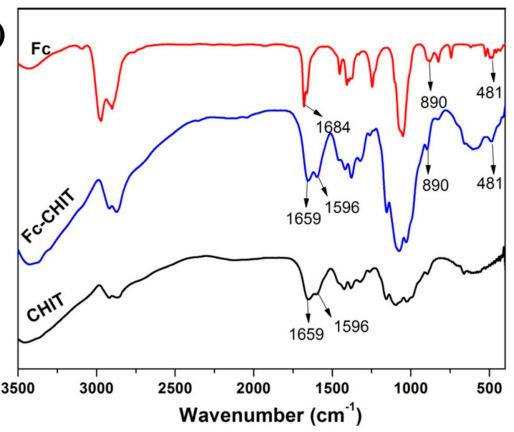

(c)

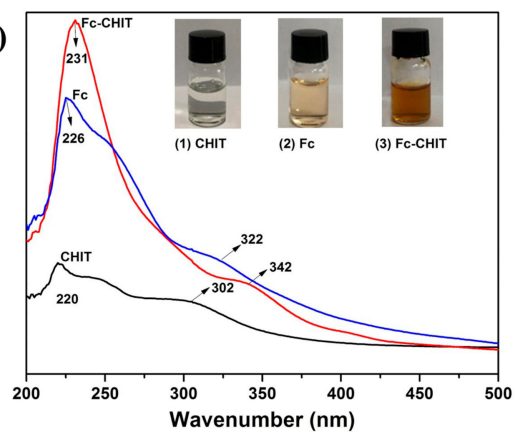

Figure 1. (a) Reaction scheme of CHIT and Fc; (b) FT-IR and (c) UV spectra of CHIT, Fc and Fc-CHIT.

Thermogravimetric analysis of Fc-CHIT is shown in Figure 2, which also shows TGA and DTA data of $\mathrm{Fc}-\mathrm{CHO}$ and chitosan. In the range of $30^{\circ} \mathrm{C}$ to $100{ }^{\circ} \mathrm{C}$, due to evaporation of water, the pristine CHIT showed small weight loss. However, there was rapid weight loss when it decomposed at $302{ }^{\circ} \mathrm{C}$. On the other hand, Fc showed large decomposition around $220^{\circ} \mathrm{C}$. The TG curve of Fc-CHIT was similar to that of $\mathrm{CHIT}$, but it lost more weight due to decomposition of $\mathrm{Fc}$ before $300^{\circ} \mathrm{C}$. The difference between TG curves indicated that the proportion of $\mathrm{Fc}_{\mathrm{C}}$ in Fc-CHIT was about $5.1 \mathrm{wt} \%$.
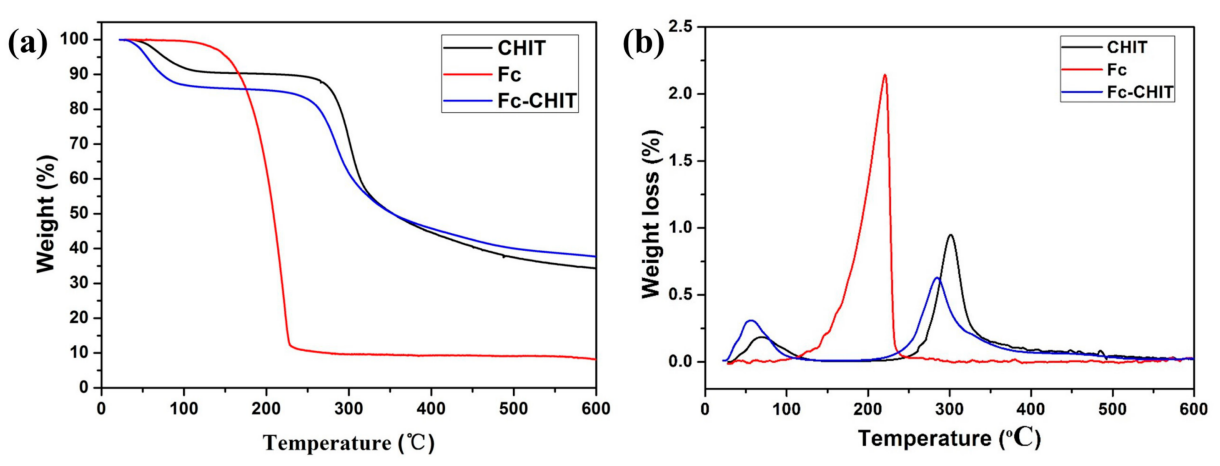

Figure 2. Thermogravimetric analysis before and after Fc-modified chitosan; (a) TGA, (b) DTG.

Microstructural morphology of Fc-CHIT/CNT@Cu composites are characterized and shown in Figure 3 using TEM and SEM. The observed agglomeration in the TEM image in Figure 3a might have resulted from the electron donor-acceptor interaction in the Fc-CHIT/CNT@Cu composite structure. In this work, $\mathrm{Cu}$ NPs were specifically dispersed into the CNT network in order to fabricate uniform Fc-CHIT/CNT@Cu composites. In Figure 3c, spherical spots appeared in the SEM image, which was the manifestation of successful $\mathrm{Cu}$ NP formation on the surface of carbon nanotube composites. From energy-dispersive spectra (EDS) of the composites (Figure 3d), it could be clearly seen that $\mathrm{C}, \mathrm{N}, \mathrm{O}, \mathrm{Cu}$ and Fe were the main components. Therefore, EDS results also showed that $\mathrm{Cu}$ NPs were successfully deposited, and Fc was incorporated into the composites. SEM of pristine CNT and Fc-CHIT/CNT are shown in Figure S1, which could not be seen in the presence of $\mathrm{Cu}$. 

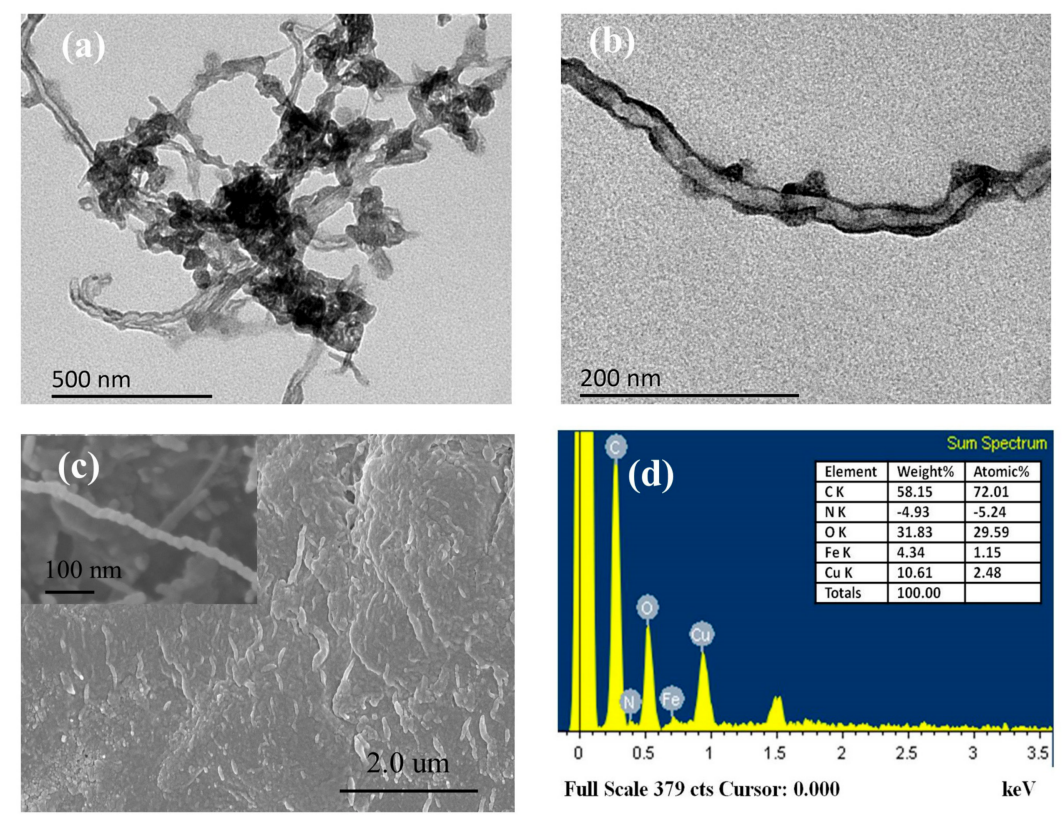

Figure 3. (a) TEM images of Fc-CHIT/CNT@Cu (b) under high magnification; (c) SEM images of Fc-CHIT/CNT@Cu and (d) energy dispersive X-ray spectrum.

\subsection{Electrochemical Measurement}

\subsubsection{Electrochemical Characterization of Modified Electrode}

Electrode surface impedance changes during the modified process could be determined using electrochemical impedance spectroscopy (EIS). All of their Nyquist plots, except Fc-CHIT/CNT, consisted of an inclined line at the low-frequency region and a semicircular part at high frequency, corresponding to the diffusion-limited process and the electron transfer limiting process, respectively. The results are shown in Figure 4. EIS plot for Fc-CHIT/CNT alone showed two semicircles that might correspond to charge transfer resistance levels at the edges and at the center [29]. The high frequency semicircle affected electron transfer dynamics in the interface of electrode/electrolyte, and its diameter corresponded to charge transfer resistance (Rct). It could be clearly observed that the CHIT/CNT showed larger Rct than bare GCE, which indicated that CHIT/CNT did not improve conductivity on the surface of GCE. On the other hand, it is worth noting that the Rct value of Fc-CHIT/CNT and CHIT/CNT@Cu was lower than that of CHIT/CNT, which indicated that the presence of Fc and $\mathrm{Cu}$ NPs could improve conductivity of the composites. Further, the Rct value of Fc-CHIT/CNT@Cu was the smallest, which showed that $\mathrm{Fc}$ and $\mathrm{Cu}$ NPs had a synergistic effect in improving conductivity. Through software analysis, Rct values of CHIT/CNT, Fc-CHIT/CNT, CHIT/CNT@Cu and Fc-CHIT/CNT@Cu were 138.60, $56.56,0.38$ and $0.14 \Omega$, respectively, which confirmed the above conclusions. This also indicated that conductive Fc and $\mathrm{Cu}$ NPs were successfully immobilized onto chitosan/CNT nanocomposites.

$\mathrm{CV}$ was performed to study Fc-CHIT/CNT@Cu electrode electro-oxidation performance towards glucose in $0.1 \mathrm{M} \mathrm{NaOH}$ electrolyte. The potential range was $-0.8 \mathrm{~V}$ to $0.6 \mathrm{~V}$ at a scan rate of $10 \mathrm{mV} \mathrm{s}^{-1}$. As shown in Figure 5a, the CHIT/CNT electrode had no obvious redox peaks with $1 \mathrm{mM}$ glucose or without glucose, confirming that $\mathrm{CHIT} / \mathrm{CNT}$ could not detect glucose electrochemically. Figure $5 \mathrm{~b}$ shows, however, that after CHIT/CNT were modified with $\mathrm{Fc}$ and $\mathrm{Cu}$ NPs, the carbon nanohybrid electrode had three anodic peaks at around $-0.3,0.4$ and $0.2 \mathrm{~V}$, which corresponded to $\mathrm{Cu} / \mathrm{Cu}$ (II), $\mathrm{Cu}$ (II)/Cu (III) and $\mathrm{Fe}$ (II)/Fe (III) redox couples. After adding $1 \mathrm{mM}$ of glucose into a $0.1 \mathrm{M}$ $\mathrm{NaOH}$ solution, the peak anodic current increased, indicating that the Fc-CHIT/CNT@Cu electrode had a response towards glucose detection. CVs and i-t test of CHIT/CNT@Cu, Fc-CHIT/CNT and Fc-CHIT/CNT@Cu in Figures S2 and S3 indicated that $\mathrm{Cu}$ and Fc had a synergistic catalysis effect to 
glucose. Some studies have shown that under alkaline conditions, electro-oxidation of glucose on the surface of $\mathrm{Cu}$ is usually accompanied by chemical valence state transition of $\mathrm{Cu}[4,30-33]$. Firstly, $\mathrm{Cu}$ is oxidized to $\mathrm{Cu}$ (II) (Equations (1)-(2)). Subsequently, $\mathrm{Cu}$ (II) is oxidized to $\mathrm{Cu}$ (III), such as $\mathrm{Cu}_{2} \mathrm{O}_{3}$ and $\mathrm{CuO}^{2-}$ (Equations (3)-(4)), and $\mathrm{Fe}$ (II) is oxidized to Fe (III) (Equation (5)). Finally, after glucose is added to the alkaline electrolyte solution, it is oxidized to gluconolactone (Equation (6)).

$$
\begin{gathered}
\mathrm{Cu}+2 \mathrm{OH}^{-} \rightarrow \mathrm{Cu}(\mathrm{OH})_{2}+2 \mathrm{e}^{-} \\
\mathrm{Cu}(\mathrm{OH})_{2} \leftrightarrow \mathrm{CuO}+\mathrm{H}_{2} \mathrm{O} \\
2 \mathrm{CuO}+2 \mathrm{OH}^{-} \leftrightarrow \mathrm{Cu}_{2} \mathrm{O}_{3}+\mathrm{H}_{2} \mathrm{O}+\mathrm{e}^{-} \\
2 \mathrm{Cu}(\mathrm{OH})_{2}+2 \mathrm{OH}^{-} \leftrightarrow \mathrm{CuO}_{2}^{-}+\mathrm{H}_{2} \mathrm{O}+\mathrm{e}^{-} \\
\mathrm{Fe}(\mathrm{II}) \leftrightarrow \mathrm{Fe}(\mathrm{III}) \\
\text { glucose } \stackrel{\mathrm{Cu}(\mathrm{III}) / \mathrm{Fe}(\mathrm{III})}{\leftrightarrow} \text { gluconolactone }+\mathrm{e}^{-}
\end{gathered}
$$

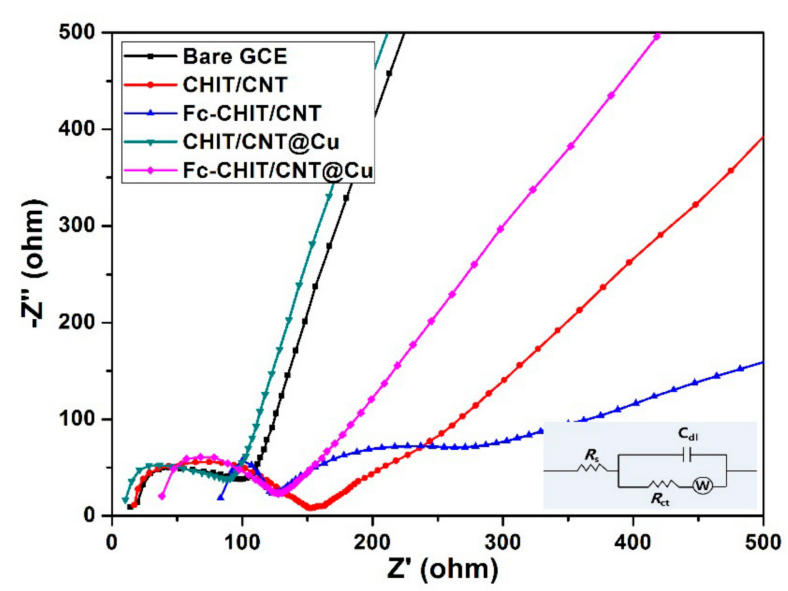

Figure 4. Nyquist plots for bare GCE, CHIT/CNT, CHIT/CNT@Cu, Fc-CHIT/CNT and Fc-CHIT/ $\mathrm{CNT@Cu}$ (inset is an equivalent circuit model). Electrolyte: $5.0 \mathrm{mM} \mathrm{Fe}(\mathrm{CN})_{6}{ }^{3-} / \mathrm{Fe}(\mathrm{CN})_{6}{ }^{4-}$ containing $0.1 \mathrm{M} \mathrm{KCl}$.

CVs at the Fc-CHIT/CNT@Cu electrode in $0.1 \mathrm{M} \mathrm{NaOH}$ solution at different scan rates of 20 to $70 \mathrm{mv} / \mathrm{s}$ are shown in Figure 5c. It displayed clearly that the peak shifted to a higher potential value as the scan rate increased. Further, the relationship between scanning rate and electrochemical behavior was also evaluated and is shown in Figure $5 \mathrm{~d}$. As the square root of the scan rate increased, the peak current at $0.44 \mathrm{~V}$ and $-0.5 \mathrm{~V}$ increased linearly. The results indicated that oxidation of glucose on the electrode surface was a diffusion-controlled reaction [34,35]. Figure S4 indicate the electrolyte $\mathrm{pH}$ and constituents will cause current values change with the same glucose concentration detection. 

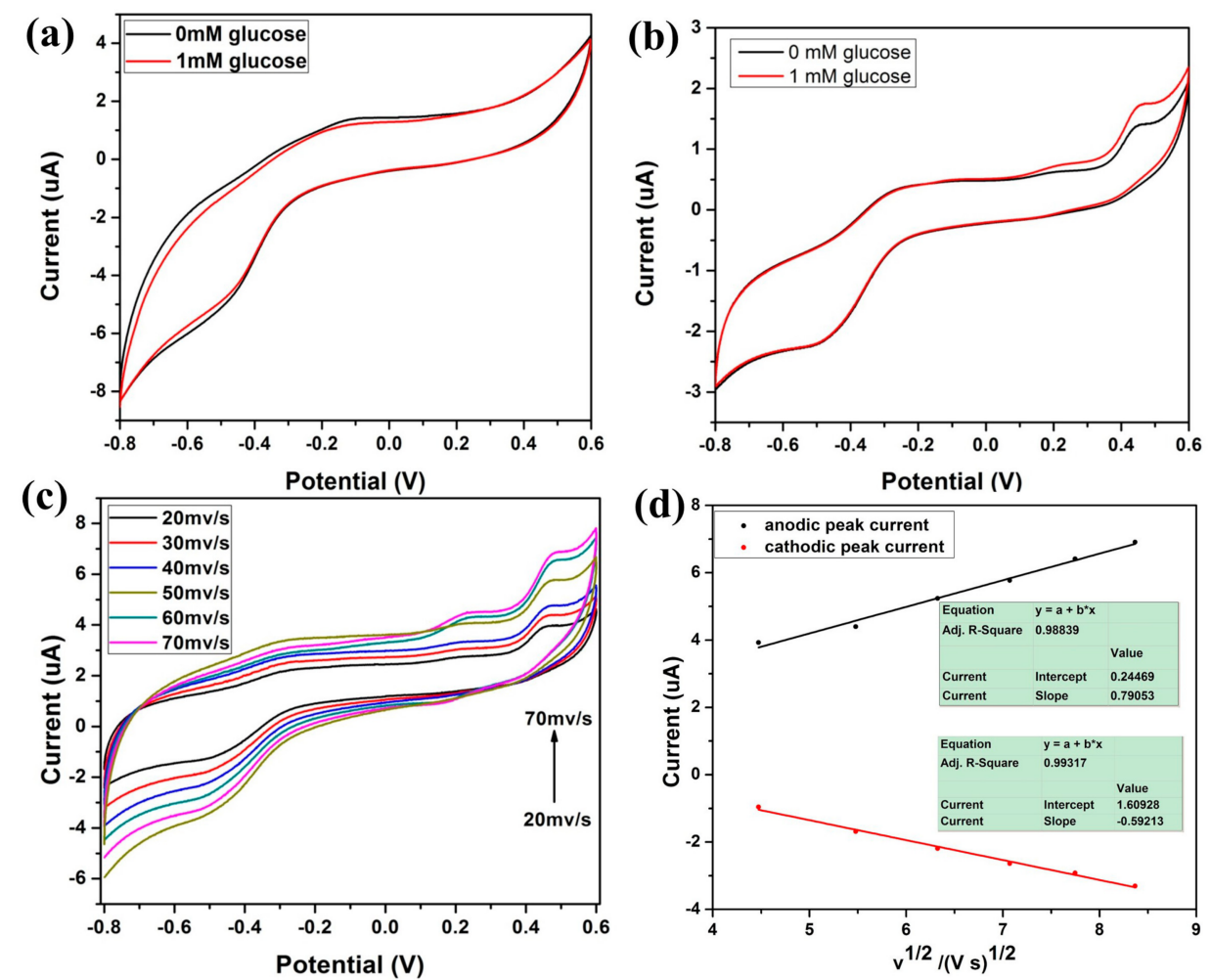

Figure 5. CVs of (a) CHIT/CNT and (b) Fc-CHIT/CNT@Cu electrodes in 0.1M NaOH electrolyte without glucose and with $1 \mathrm{mM}$ glucose. (c) CVs of the Fc-CHIT/CNT@Cu electrode in 0.1M NaOH electrolyte at scan rates of 20,30, 40,50, 60 and $70 \mathrm{mV} / \mathrm{s}$. (d) Plots of anodic and cathodic peak currents versus scan rates $\left(\mathrm{v}^{1 / 2}\right)$.

\subsubsection{Electrochemical Activity of Fc-CHIT/CNT@Cu towards Glucose Detection}

Analytical characterization of Fc-CHIT/CNT@Cu/GCE, based on chronoamperometric measurements, was performed, and the applied potential was equal to $0.44 \mathrm{~V}$, based on the $\mathrm{CV}$ curve. The results in Figure 6 showed that after adding a glucose solution, the oxidation current could reach a steady state within $2 \mathrm{~s}$. There was a linear relationship between the oxidation current value and glucose concentration in the range of $0.2 \mathrm{mM}$ to $22 \mathrm{mM}$. The calibration curve for glucose concentration was shown as $\operatorname{Ip}(\mu \mathrm{A})=0.120$ [glucose] $(\mathrm{mM})+0.810(\mu \mathrm{A})$. Sensitivity of the proposed sensor was calculated as $1.256 \mathrm{uA} \mathrm{mM}-1 \mathrm{~cm}^{-2}$. Good sensitivity could be attributed to the synergy between ferrocene and $\mathrm{Cu} N$ Ps. When the signal-to-noise ratio was $3(\mathrm{~S} / \mathrm{N}=3)$, the limit of detection (LOD) was determined from the linearity range of the calibration curve based on the following equation:

$$
L O D=\frac{3 \sigma}{s}
$$

where $\sigma$ is the standard deviation of blank solution (11 readings), and $s$ is the slope of the chronoamperometric calibration curve. LOD of the proposed sensor was $13.52 \mu \mathrm{M}$. Compared with other electrochemical methods described in literature (Table 1), the detection limit of our proposed biosensor for glucose detection remained at a similar level with high sensitivity. 

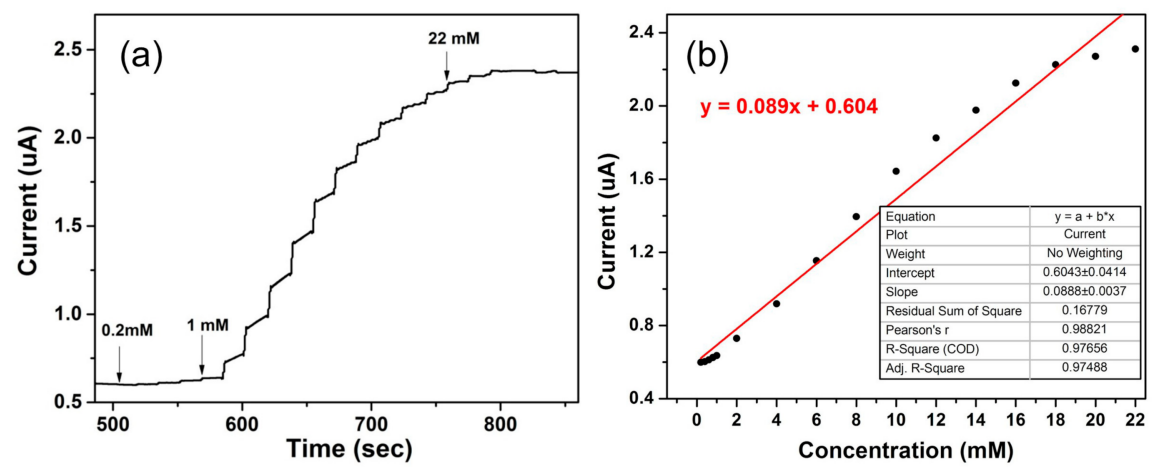

Figure 6. (a) Amperometric i-t curve response of serial concentrations of glucose obtained at the Fc-CHIT/CNT@Cu electrode. The difference in the concentration of glucose was marked with arrow lines. (b) Plot for linear variation of current vs. glucose concentration of range of Fc-CHIT/CNT@Cu electrode (in glucose concentration range of $0.2-22 \mathrm{mM}$ ). Conditions: supporting electrolyte, $0.1 \mathrm{M}$ $\mathrm{NaOH}$; operating potential, $0.44 \mathrm{~V}$.

Table 1. Comparison of glucose detection using various sensing electrodes.

\begin{tabular}{cccccc}
\hline Modified Electrode & $\begin{array}{c}\text { LOD } \\
(\boldsymbol{\mu M})\end{array}$ & $\begin{array}{c}\text { Linear Range } \\
(\mathbf{m M})\end{array}$ & $\begin{array}{c}\text { Sensitivity } \\
\left(\mu \mathbf{A m M}^{-\mathbf{1}} \mathbf{c m}^{-2}\right)\end{array}$ & $\begin{array}{c}\text { Electrolyte } \\
\mathbf{p H}\end{array}$ & Ref. \\
\hline Cu@CHIT-CNT & $5 \times 10^{-2}$ & $0.5 \times 10^{-3} \sim 1$ & Not mentioned & 12.7 & {$[36]$} \\
AuNPs-MWCNTs-CHIT cryogel & 0.5 & $1 \times 10^{-3} \sim 1$ & Not mentioned & 12.7 & {$[37]$} \\
Cu/NiNPs/CMWCNTs-ITO & 0.67 & $1 \times 10^{-3} \sim 1$ & 6.782 & 13 & {$[31]$} \\
rGO-Fc/GA-GOx/GCE & $2 \times 10^{-2}$ & $2 \sim 10 \times 10^{-3}$ & Not mentioned & 7.4 & {$[6]$} \\
CuNPs/NGO & 0.44 & $0.001 \sim 1.803$ & 2500 & 13 & {$[38]$} \\
Cu/CuO/ZnO & 18 & $0.1 \sim 1$ & 408 & 13 & {$[39]$} \\
AuCu/CNTs & 4 & $0.08 \sim 9.260$ & 22 & 13 & {$[40]$} \\
Cu NPs/SWCNTs & 0.3 & $0.5 \sim 500 \times 10^{-3}$ & 0.256 & 12.3 & {$[41]$} \\
Cu/Co NWs & $5 \times 10^{-2}$ & $0.3 \sim 2.6 \times 10^{-3}$ & 0.097 & 13.7 & {$[42]$} \\
Cu nanoporous & 40 & $0.01 \sim 0.5$ & 220 & 13.3 & {$[43]$} \\
S-rGO/CuS & 0.032 & up to 20.17 & 429.4 & 13 & {$[44]$} \\
CuO-6 & 0.307 & up to 5.664 & 992.073 & 12.7 & {$[45]$} \\
CuO-CS/GCE & 11 & $0.05 \sim 1$ & 503.129 & 13 & {$[46]$} \\
Fc-CHIT/CNT@Cu/GCE & 13.52 & $0.2 \sim 22$ & 1.256 & 13 & This work \\
\hline
\end{tabular}

\subsubsection{Selectivity and Stability of the Biosensor}

The amperometric response of the Fc-CHIT/CNT@Cu sensor with the addition of typical biological interferences, such as ascorbic acid (AA), dopamine (DA) and uric acid (UA), to the glucose solution was determined in order to evaluate the biosensor's selectivity. Compared with normal physiological levels of glucose (3-8 mM), the interfering species' levels were much lower, such as AA (about $0.1 \mathrm{mM}$ ), DA (about $0.02 \mathrm{mM}$ ), UA (about $0.02 \mathrm{mM}$ ) and so on [47].

The current value changes were tested at different potentials (Figure 7a) with the addition of AA, DA, UA or $1 \mathrm{mM}$ glucose. It could be seen that there was almost no response current of AA and DA below $0.4 \mathrm{~V}$, and all current values increased to a higher potential. However, the three interferences caused slight current changes when compared to the addition of glucose. As shown in Figure $7 \mathrm{~b}$, under $0.44 \mathrm{~V}$ working potential, the addition of $0.1 \mathrm{mM}$ AA caused a slight current response, and there were no obvious responses to $0.02 \mathrm{mM}$ DA and UA. However, after adding $8 \mathrm{mM}$ glucose, the sensor had an obvious response. Figure S5 is the selectivity of the elctrodes with different electrolyte $\mathrm{pH}$ and constituents. These results indicated that Fc-CHIT/CNT@Cu was beneficial to the conductivity of the enzyme-free glucose sensor with good selectivity, and it could reduce the interference of electroactive substances, which is more favorable to practical applications. 

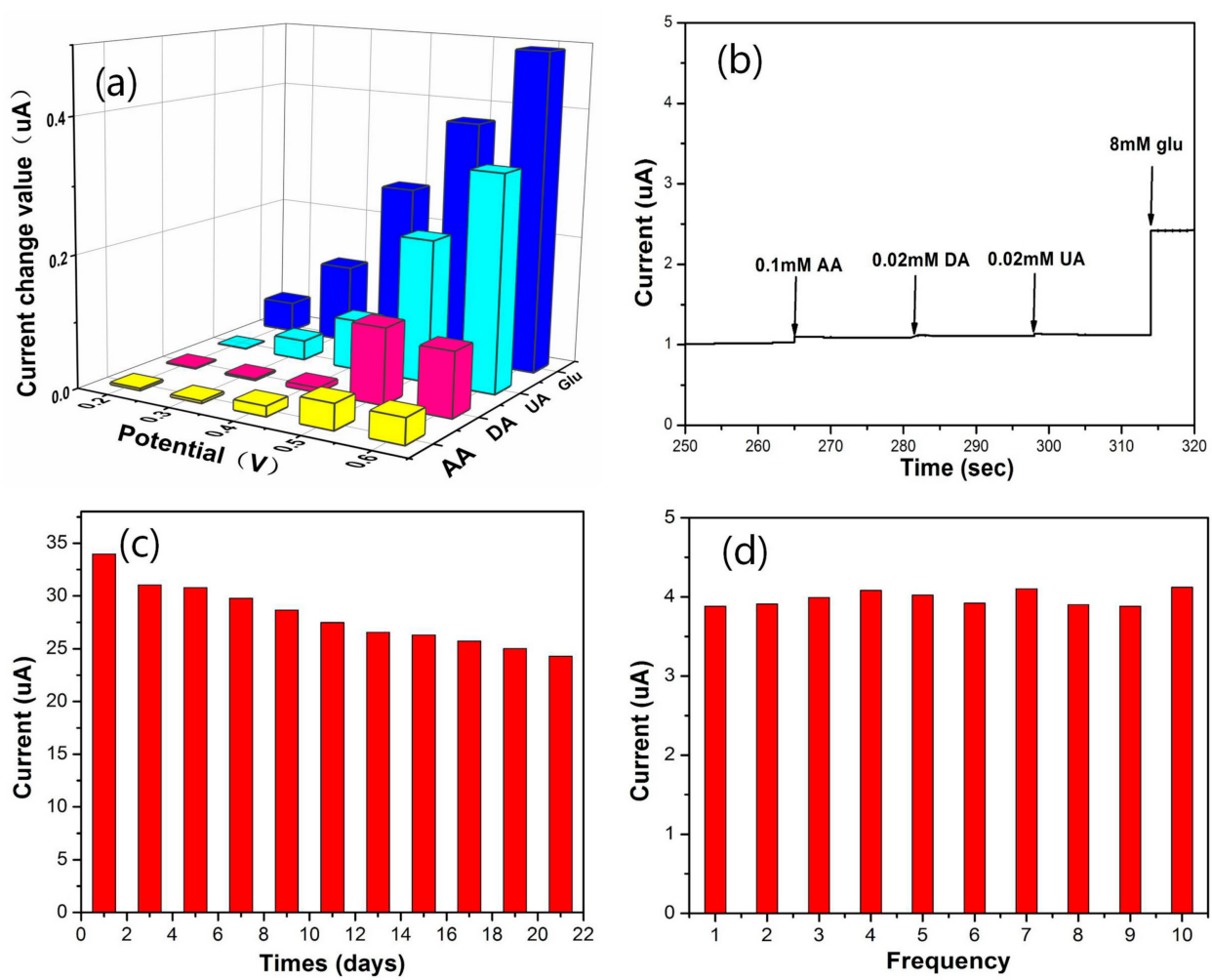

Figure 7. Current values of the Fc-CHIT/CNT@Cu electrode with the addition of ascorbic acid (AA), dopamine (DA), uric acid (UA) and glucose $(0.1 \mathrm{M} \mathrm{NaOH})$ (a) under different applied potentials; (b) under $0.44 \mathrm{~V}$ applied potential; (c) study of sensor stability over 7 days with addition of $4 \mathrm{mM}$ glucose; (d) repeatability was measured by 10 successive measurements of the same sensor at $0.44 \mathrm{~V}$ potential, with addition of $4 \mathrm{mM}$ glucose.

The long-term stability of glucose detection of the modified electrode was then assessed. The Fc-CHIT/CNT@Cu-modified electrode was stored at $4{ }^{\circ} \mathrm{C}$ during this study. The current response to $4 \mathrm{mM}$ glucose was checked every day using amperometry, after the baseline was tested in a $0.1 \mathrm{M} \mathrm{NaOH}$ electrolyte solution. As shown in Figure 7c, the current retained about $94 \%$ of the initial value after seven days, which indicated that Fc-CHIT/CNT@Cu could be regarded as a stable glucose sensor. Reliable reproducibility was also an important part of evaluating the sensor's actual performance. As seen in Figure 7d, the RSD was only 3.3\%, which indicated that the sensor showed good reproducibility.

\section{Conclusions}

In the current study, ferrocene was covalently linked with chitosan via the Schiff-base reaction. In the next step, using a chemical reduction method, we obtained CNT@Cu nanohybrids. The most prominent achievement of this work was the construction of a ferrocene-branched chitosan/CNT@Cu/GCE nanohybrid biosensor for enzyme-free glucose determination. The structure and morphology of the composite electrode were studied. The electrode showed excellent glucose detection performance (wide linear range, low detection limit, high sensitivity), which was due to the large specific surface area of the carbon nanotube, good conductivity of $\mathrm{Cu}$ NPs and a certain synergistic effect of Fc with unique redox behavior. In addition, the sensor had good selectivity and long-term stability. Therefore, the Fc-CHIT/CNT@Cu electrode has promising potential for glucose detection. 
Supplementary Materials: The following are available online at http://www.mdpi.com/2073-4360/12/10/2419/s1, Figure S1: SEM of (a) pristine CNT and (b) Fc-CHIT/CNT, inset images are the EDS and element content, Figure S2: CVs of Fc-CHIT/CNT, CHIT/CNT@Cu and Fc-CHIT/CNT@Cu electrodes in 0.1 M NaOH electrolyte (a) without glucose and (b) with $1 \mathrm{mM}$ glucose, Figure S3: The relationship between glucose concentration and current value of CHIT/CNT@Cu, Fc-CHIT/CNT and Fc-CHIT/CNT@Cu modified GCE electrodes, Figure S4. (a) Chronoamperograms obtained with different $\mathrm{NaOH}$ concentrations and $0.1 \mathrm{M} \mathrm{KOH}$; (b) Current values of $\mathrm{NaOH}$ concentrations or $0.1 \mathrm{M} \mathrm{KOH}$ with $4 \mathrm{mM}$ glucose, Figure S5: The current response of the Fc-CHIT/CNT@Cu electrode to the addition of AA, DA, UA, glucose with different electrolyte $\mathrm{pH}$ and constituents.

Author Contributions: Project administration, F.W.; Investigation, S.H.; data citation, S.H.; Wring-review and editing, F.W.; Writing-original draft, F.S. and J.L.; Writing-review \& editing, K.H. and F.W. All authors have read and agreed to the published version of the manuscript.

Funding: This research received no external funding.

Acknowledgments: We thank the Advanced Analysis and Testing Center of Nanjing Forestry University very much for TEM measurements.

Conflicts of Interest: The authors declare no conflict of interest.

\section{References}

1. Cho, N.H.; Shaw, J.E.; Karuranga, S.; Huang, Y.; Fernandes, J.D.R.; Ohlrogge, A.; Malanda, B. IDF Diabetes Atlas: Global estimates of diabetes prevalence for 2017 and projections for 2045. Diabetes Res. Clin. Pr. 2018, 138, 271-281. [CrossRef] [PubMed]

2. Cao, X.; Ning, W.; Jia, S.; Shao, Y. Detection of glucose based on bimetallic PtCu nanochains modified electrodes. Anal. Chem. 2013, 85, 5040-5046. [CrossRef] [PubMed]

3. Hu, Y.; Jiang, X.; Zhang, L.; Fan, J.; Wu, W. Construction of near-infrared photonic crystal glucose-sensing materials for ratiometric sensing of glucose in tears. Biosens. Bioelectron. 2013, 48, 94-99. [CrossRef] [PubMed]

4. Chakraborty, P.; Dhar, S.; Deka, N.; Debnath, K.; Mondal, S.P. Non-enzymatic salivary glucose detection using porous $\mathrm{CuO}$ nanostructures. Sens. Actuators B Chem. 2020, 302, 127134. [CrossRef]

5. Kamyabi, M.A.; Hajari, N.; Turner, A.P.; Tiwari, A. A high-performance glucose biosensor using covalently immobilised glucose oxidase on a poly(2,6-diaminopyridine)/carbon nanotube electrode. Talanta 2013, 116, 801-808. [CrossRef]

6. Matysiak-Brynda, E.; Sęk, J.P.; Kasprzak, A.; Królikowska, A.; Donten, M.; Patrzalek, M.; Poplawska, M.; Nowicka, A.M. Reduced graphene oxide doping with nanometer-sized ferrocene moieties-New active material for glucose redox sensors. Biosens. Bioelectron. 2019, 128, 23-31. [CrossRef]

7. Li, H.; Zhao, F.; Yue, L.; Li, S.; Xiao, F. Nonenzymatic electrochemical biosensor based on novel hydrophilic ferrocene-terminated hyperbranched polymer and its application in glucose detection. Electroanalysis 2015, 28, 1003-1011. [CrossRef]

8. Grochowska, K.; Ryl, J.; Karczewski, J.; Śliwiński, G.; Cenian, A.; Siuzdak, K. Non-enzymatic flexible glucose sensing platform based on nanostructured $\mathrm{TiO}_{2}-\mathrm{Au}$ composite. J. Electroanal. Chem. 2019, 837, $230-239$. [CrossRef]

9. Tabassum, S.; Naz, S.; Nisar, A.; Sun, H.; Karim, S.; Khan, M.; Shahzada, S.; Rahman, A.U.; Ahmad, M.; Tabussam, S.; et al. Synergic effect of plasmonic gold nanoparticles and graphene oxide on the performance of glucose sensing. New J. Chem. 2019, 43, 18925-18934. [CrossRef]

10. Gao, W.; Li, Q.; Dou, M.; Zhang, Z.; Wang, F. Self-supported Ni nanoparticles embedded on nitrogen-doped carbon derived from nickel polyphthalocyanine for high-performance non-enzymatic glucose detection. J. Mater. Chem. B 2018, 6, 6781-6787. [CrossRef]

11. Mei, H.; Wu, W.; Yu, B.; Li, Y.; Wu, H.; Wang, S.; Xia, Q. Non-enzymatic sensing of glucose at neutral pH values using a glassy carbon electrode modified with carbon supported Co@Pt core-shell nanoparticles. Microchim. Acta 2015, 182, 1869-1875. [CrossRef]

12. Jiang, J.; Zhang, P.; Liu, Y.; Luo, H. A novel non-enzymatic glucose sensor based on a Cu-nanoparticle-modified graphene edge nanoelectrode. Chem. Sci. 2017, 9, 2205-2210. [CrossRef]

13. Prakash, S.; Chakrabarty, T.; Singh, A.K.; Shahi, V.K. Polymer thin films embedded with metal nanoparticles for electrochemical biosensors applications. Biosens. Bioelectron. 2013, 41, 43-53. [CrossRef] 
14. Zhao, J.; Wei, L.; Peng, C.; Su, Y.; Yang, Z.; Zhang, L.; Wei, H.; Zhang, Y. A non-enzymatic glucose sensor based on the composite of cubic $\mathrm{Cu}$ nanoparticles and arc-synthesized multi-walled carbon nanotubes. Biosens. Bioelectron. 2013, 47, 86-91. [CrossRef] [PubMed]

15. Ismail, N.S.; Le, Q.H.; Yoshikawa, H.; Saito, M.; Tamiya, E. Development of non-enzymatic electrochemical glucose sensor based on graphene oxide nanoribbon-gold nanoparticle hybrid. Electrochim. Acta 2014, 146, 98-105. [CrossRef]

16. Banks, C.E.; Crossley, A.; Salter, C.; Wilkins, S.J.; Compton, R.G. Carbon nanotubes contain metal impurities which are responsible for the "electrocatalysis" seen at some nanotube-modified electrodes. Angew. Chem. Int. Ed. Engl. 2006, 45, 2533-2537. [CrossRef] [PubMed]

17. Zhou, M.; Li, Y.; Gong, Q.; Xia, Z.; Yang, Y.; Liu, X.; Wang, J.; Gao, Q. Polythiophene grafted onto single-wall carbon nanotubes through oligo(ethylene oxide) linkages for supercapacitor devices with enhanced electrochemical performance. ChemElectroChem 2019, 6, 4595-4607. [CrossRef]

18. Başkaya, G.; Yıldız, Y.; Savk, A.; Okyay, T.O.; ERiŞ, S.; Sert, H.; Şen, F. Rapid, sensitive, and reusable detection of glucose by highly monodisperse nickel nanoparticles decorated functionalized multi-walled carbon nanotubes. Biosens. Bioelectron. 2017, 91, 728-733. [CrossRef]

19. Sun, Y.P.; Fu, K.; Lin, Y.; Huang, W. Functionalized carbon nanotubes: Properties and applications. Acc. Chem. Res. 2002, 35, 1096-1104. [CrossRef]

20. Zanella, R.; Basiuk, V.A.; Santiago, P.; Basiuk, V.A.; Mireles, E.; Puente-Lee, I.; Saniger, J.M. Deposition of gold nanoparticles onto thiol-functionalized multiwalled carbon nanotubes. J. Phys. Chem. B 2005, 109, 16290-16295. [CrossRef]

21. Miao, C.; Zhang, A.; Xu, Y.; Chen, S.; Ma, F.; Huang, C.; Jia, N.-Q. An ultrasensitive electrochemiluminescence sensor for detecting diphenhydramine hydrochloride based on 1-cysteine-functionalized multiwalled carbon nanotubes/gold nanoparticles nanocomposites. Sens. Actuators B Chem. 2015, 213, 5-11. [CrossRef]

22. Jiang, Y.; Lan, Y.; Yin, X.; Yang, H.; Cui, J.; Zhu, T.; Li, G. Polydopamine-based photonic crystal structures. J. Mater. Chem. C 2013, 1, 6136. [CrossRef]

23. Kavosi, B.; Salimi, A.; Hallaj, R.; Amani, K. A highly sensitive prostate-specific antigen immunosensor based on gold nanoparticles/PAMAM dendrimer loaded on MWCNTS/chitosan/ionic liquid nanocomposite. Biosens. Bioelectron. 2014, 52, 20-28. [CrossRef]

24. Kalita, G.; Sharma, S.; Wakita, K.; Umeno, M.; Hayashi, Y.; Tanemura, M. A photoinduced charge transfer composite of graphene oxide and ferrocene. Phys. Chem. Chem. Phys. 2013, 15, 1271-1274. [CrossRef]

25. Tan, G.; Qiu, Y.; Qiu, Y.; Huang, W.; Fan, H.; Ren, B. Supercapacitors based on polyelectrolyte/ ferrocenyl-surfactant complexes with high rate capability. RSC Adv. 2016, 6, 31632-31638. [CrossRef]

26. Lin, K.Y.A.; Lin, J.T.; Yang, H. Ferrocene-modified chitosan as an efficient and green heterogeneous catalyst for sulfate-radical-based advanced oxidation process. Carbohydr. Polym. 2017, 173, 412-421. [CrossRef]

27. Jha, N.; Ramaprabhu, S. Synthesis and thermal conductivity of copper nanoparticle decorated multiwalled carbon nanotubes based nanofluids. J. Phys. Chem. C 2008, 112, 9315-9319. [CrossRef]

28. Xu, Y.; Wang, L.; Li, Y.K.; Wang, C.Q. Oxidation and $\mathrm{pH}$ responsive nanoparticles based on ferrocene-modified chitosan oligosaccharide for 5-fluorouracil delivery. Carbohydr. Polym. 2014, 114, 27-35. [CrossRef]

29. Rabti, A.; Mayorga-Martinez, C.C.; Baptista-Pires, L.; Raouafi, N.; Merkoçi, A. Ferrocene-functionalized graphene electrode for biosensing applications. Anal. Chim. Acta 2016, 926, 28-35. [CrossRef]

30. Ma, P.; Xiaoyan, M.; Suo, Q.; Chen, F. Cu NPs@NiF electrode preparation by rapid one-step electrodeposition and its sensing performance for glucose. Sens. Actuators B Chem. 2019, 292, 203-209. [CrossRef]

31. Zhang, C.; Li, F.; Huang, S.; Li, M.; Guo, T.; Mo, C.; Pang, X.; Chen, L.; Li, X. In-situ facile preparation of highly efficient copper/nickel bimetallic nanocatalyst on chemically grafted carbon nanotubes for nonenzymatic sensing of glucose. J. Colloid Interface Sci. 2019, 557, 825-836. [CrossRef] [PubMed]

32. Khosroshahia, Z.; Karimzadeh, F.; Kharazihaa, M.; Allafchianb, A. A non-enzymatic sensor based on three-dimensional graphene foam decorated with $\mathrm{Cu}-\mathrm{xCu} 2 \mathrm{O}$ nanoparticles for electrochemical detection of glucose and its application in human serum. Mater. Sci. Eng. C 2020, 108, 110216. [CrossRef] [PubMed]

33. Teimuri-Mofrad, R.; Aghaiepour, A.; Rahimpour, K. A convenient method for synthesis of novel alkylferrocene derivatives with various functional groups: Synthesis, characterization and electrochemical investigation. J. Iran. Chem. Soc. 2020, 17, 2449-2462. [CrossRef]

34. Jiang, Z.; Shangguan, Y.; Zheng, Q. Ferrocene-modified polyelectrolyte film-coated electrode and its application in glucose detection. Polymers 2019, 11, 551. [CrossRef] 
35. Yuan, Y.; Wang, Y.; Wang, H.; Hou, S. Gold nanoparticles decorated on single layer graphene applied for electrochemical ultrasensitive glucose biosensor. J. Electroanal. Chem. 2019, 855, 113495. [CrossRef]

36. Ensafi, A.A.; Jafari-Asl, M.; Dorostkar, N.; Ghiaci, M.; Martínez-Huerta, M.V.; Fierro, J.L.G. The fabrication and characterization of $\mathrm{Cu}$-nanoparticle immobilization on a hybrid chitosan derivative-carbon support as a novel electrochemical sensor: Application for the sensitive enzymeless oxidation of glucose and reduction of hydrogen peroxide. J. Mater. Chem. B 2014, 2, 706-717. [CrossRef]

37. Kangkamano, T.; Numnuam, A.; Limbut, W.; Kanatharana, P.; Thavarungkul, P. Chitosan cryogel with embedded gold nanoparticles decorated multiwalled carbon nanotubes modified electrode for highly sensitive flow based non-enzymatic glucose sensor. Sens. Actuators B Chem. 2017, 246, 854-863. [CrossRef]

38. Sivasankar, K.; Rani, K.K.; Wang, S.F.; Devasenathipathy, R.; Lin, C.H. Copper nanoparticle and nitrogen doped graphite oxide based biosensor for the sensitive determination of glucose. Nanomaterials 2018, 8, 429. [CrossRef]

39. SoYoon, S.; Ramadoss, A.; Saravanakumar, B.; Kim, S.J. Novel Cu/CuO/ZnO hybrid hierarchical nanostructures for non-enzymatic glucose sensor application. J. Electroanal. Chem. 2014, 717-718, 90-95. [CrossRef]

40. Liu, D.; Luo, Q.; Zhou, F. Nonenzymatic glucose sensor based on gold-copper alloy nanoparticles on defect sites of carbon nanotubes by spontaneous reduction. Synth. Met. 2010, 160, 1745-1748. [CrossRef]

41. Male, K.B.; Hrapovic, S.; Liu, Y.; Wang, D.; Luong, J.H. Electrochemical detection of carbohydrates using copper nanoparticles and carbon nanotubes. Analytica Chimica Acta 2004, 516, 35-41. [CrossRef]

42. Gupta, J.; Arya, S.; Verma, S.; Singh, A.; Sharma, A.; Singh, B.; Prerna; Sharma, R. Performance of template-assisted electrodeposited Copper/Cobalt bilayered nanowires as an efficient glucose and Uric acid senor. Mater. Chem. Phys. 2019, 238, 121969. [CrossRef]

43. Sattayasamitsathit, S.; Thavarungkul, P.; Thammakhet, C.; Limbut, W.; Numnuam, A.; Buranachai, C.; Kanatharana, P. Fabrication of nanoporous copper film for electrochemical detection of glucose. Electroanalysis 2009, 21, 2371-2377. [CrossRef]

44. Karikalan, N.; Karthik, R.; Chen, S.M.; Karuppiah, C.; Elangovan, A. Sonochemical synthesis of sulfur doped reduced graphene oxide supported CuS nanoparticles for the non-enzymatic glucose sensor applications. Sci. Rep. 2017, 7, 2494. [CrossRef]

45. Yang, P.; Wang, X.; Ge, C.Y.; Fu, X.; Liu, X.Y.; Chai, H.; Guo, X.; Yao, H.C.; Xu, C.; Chen, K. Fabrication of $\mathrm{CuO}$ nanosheets-built microtubes via Kirkendall effect for non-enzymatic glucose sensor. Appl. Surf. Sci. 2019, 494, 484-491. [CrossRef]

46. Figiela, M.; Wysokowski, M.; Galiński, M.; Jesionowski, T.; Stepniak, I. Synthesis and characterization of novel copper oxide-chitosan nanocomposites for non-enzymatic glucose sensing. Sens. Actuators B Chem. 2018, 272, 296-307. [CrossRef]

47. Lu, L.; Kang, J. Amperometric nonenzymatic sensing of glucose at very low working potential by using a nanoporous PdAuNi ternary alloy. Microchim. Acta 2018, 185, 111. [CrossRef]

Publisher's Note: MDPI stays neutral with regard to jurisdictional claims in published maps and institutional affiliations.

(C) 2020 by the authors. Licensee MDPI, Basel, Switzerland. This article is an open access article distributed under the terms and conditions of the Creative Commons Attribution (CC BY) license (http://creativecommons.org/licenses/by/4.0/). 